\title{
BMJ Open Association between active tobacco use during pregnancy and infant respiratory health: a systematic review and meta- analysis
}

\author{
Ediane De Queiroz Andrade (D , ,,2 Carla Rebeca Da Silva Sena, ${ }^{1,2}$ \\ Adam Collison, ${ }^{1,2}$ Vanessa E Murphy, ${ }^{1,2}$ Gillian Sandra Gould (i) , ${ }^{2}$ Billie Bonevski, ${ }^{2}$ \\ Joerg Mattes ${ }^{1,2,3}$
}

To cite: De Queiroz Andrade E, Da Silva Sena CR, Collison A, et al. Association between active tobacco use during pregnancy and infant respiratory health: a systematic review and meta-analysis. BMJ Open 2020;10:e037819. doi:10.1136/ bmjopen-2020-037819

- Prepublication history and additional material for this paper are available online. To view these files, please visit the journal online (http://dx.doi. org/10.1136/bmjopen-2020037819).

Received 18 February 2020 Revised 27 June 2020

Accepted 14 August 2020

Check for updates

(C) Author(s) (or their employer(s)) 2020. Re-use permitted under CC BY-NC. No commercial re-use. See rights and permissions. Published by BMJ.

For numbered affiliations see end of article.

\section{Correspondence to}

Dr Ediane De Queiroz Andrade; ediane.dequeirozandrade@uon. edu.au and

Dr Joerg Mattes;

joerg.mattes@newcastle.edu.au

\section{ABSTRACT}

Objective To evaluate what is known about active tobacco use during pregnancy and the association with infant respiratory health.

Design Systematic review and meta-analysis using the Preferred Reporting Items for Systematic Reviews and Meta-Analyses guidelines.

Data sources MEDLINE, EMBASE, Cochrane, CINAHL, and Maternity and Infant Care were searched thoroughly until June 2020.

Eligibility criteria for selecting studies We included case-control and cohort studies estimating the association between active tobacco use during pregnancy and infant respiratory health (wheezing and apnoea) and lung function parameters in the first 12 months of life.

Data extraction and synthesis Extraction and risk of bias assessment were conducted by two independent reviewers. The odds ratio, relative risk and mean differences were pooled with a $95 \% \mathrm{Cl}$ using the generic inverse variance method. Heterogeneity was assessed and expressed by percentage using $\mathrm{l}^{2}$.

Results We identified 4423 abstracts, and 21 publications met the eligibility criteria. Pooled OR showed an increase in wheezing episodes in infants born to mothers who were active tobacco users during pregnancy (OR 1.50, 95\% Cl 1.27 to $1.77, p<0.01$ ). Mixed results were found on lung function parameters, and a meta-analysis including two studies with comparable methodology showed a trend towards reduced maximum flow rate at functional residual capacity of $-34.59 \mathrm{~mL} / \mathrm{s}(95 \% \mathrm{Cl}-72.81$ to $3.63, \mathrm{p}=0.08)$ in 1-month-old infants born to women who smoked during pregnancy. A higher risk of apnoea was described for infants born to mothers who used smokeless tobacco during pregnancy, while the results in infants born to women who actively smoked tobacco during pregnancy were non-conclusive.

Conclusion Infants born to mothers who actively smoked during pregnancy are at higher odds of having wheeze and may have lower lung function. Smokeless tobacco use in pregnancy may increase the risk of apnoea in infancy.

PROSPERO registration number CRD42018083936.
Strengths and limitations of this study

- We systematically reviewed and meta-analysed data investigating an association between tobacco use in pregnancy and respiratory health in infants, which addresses a significant gap in the current literature.

- We identified high-quality evidence for tobacco use in pregnancy being associated with the development of wheeze in infancy, substantiating the harmful effects of tobacco on infant health.

- We found that most studies assessed tobacco use by self-reporting, which may be subject to bias and possibly underestimate the harmful effects.

Different approaches in measuring, analysing and reporting infant lung function data limited our ability to include most studies into a meta-analysis.

\section{INTRODUCTION}

Tobacco contains a complex mixture of more than 7000 chemicals, including nicotine, which is highly addictive. Most commonly, tobacco is smoked, but smokeless preparations are also consumed. Tobacco use in pregnancy is a significant risk factor for adverse infant health outcomes.

The estimated prevalence of smoking during pregnancy worldwide can vary from less than $1 \%$ in Senegal to almost $39 \%$ in Ireland. Globally, $53 \%$ of women who smoked daily continued to smoke during pregnancy. ${ }^{1}$ In Australia, this prevalence has been decreasing since 2009 , when $15 \%$ of women reported having smoked at any time during pregnancy, to $10 \%$ in $2017 .^{2}$ The majority of these women $(73 \%)$ report to have smoked after 20 weeks of pregnancy. ${ }^{3}$ However, in vulnerable groups and priority populations that experience significant health inequities, such as Indigenous women, and those living in low socioeconomic circumstances and 
geographically remote locations, the prevalence is up to $55 \%{ }^{2}$

Smokeless tobacco (ST) is another form of tobacco product, which can be used nasally or orally. ${ }^{4}$ More than 40 types of ST are consumed worldwide, including snuff, snus (moist snuff), chew and others. ST is more commonly used by women, with particularly high rates of consumption in some areas of South-East Asia, varying from $18 \%$ in India to $28 \%$ in Bangladesh. ${ }^{5}$ In contrast, Australia has a low user rate of these products (from $0.3 \%$ to $0.4 \%$ ) as its commercialisation is banned. ${ }^{6}$ Similar to smoking, the prevalence of ST use in vulnerable groups and priority populations is higher than in non-vulnerable groups. Pituri is the most common form of ST product used by the Australian Aboriginal population, and its consumption usually continues throughout pregnancy, childbirth and lactation. ${ }^{7}$

Although some women quit tobacco use when they learn about their pregnancy, many return to smoking following birth. A systematic review conducted by Jones et $a l^{8}$ in 2016 showed that only $13 \%$ of women were able to stop smoking throughout pregnancy, and of these $43 \%$ restarted smoking by 6 months post partum.

Fetal exposure to tobacco smoke is the most common modifiable risk associated with neonatal morbidity and mortality. ${ }^{9}$ Studies have shown profound effects of tobacco smoke on the placenta's intrinsic vasculature and function. ${ }^{10}{ }^{11}$ Increased branching and enlargement of the fetoplacental circulation occur as a compensatory mechanism. However, the cumulative effect of maternal smoking on the early gestation results in impaired placental function with resultant intrauterine growth restriction. ${ }^{12}$

In utero exposure to cigarette smoke has been associated with severe adverse pregnancy outcomes leading to consequences such as preterm birth, stillbirth, congenital anomalies, ${ }^{13}$ low birth weight ${ }^{14}$ and neonatal mortality, ${ }^{14}$ as well as adverse effects on immune function and fetal lung growth. ${ }^{15}{ }^{16}$ Smoking throughout pregnancy adversely influences fetal lung growth, and infants fail to reach maximum growth in later childhood with implications for their lung function throughout life. ${ }^{17}$ These outcomes can be partially explained by the effects of tobacco smoking and nicotine exposure in utero, which may cause abnormal growth and an inflammatory process in the small airways. ${ }^{1819}$

A birth cohort that evaluated children from birth to 20 years of age found a higher risk for asthma in subjects born to mothers who smoked during pregnancy (adjusted hazard ratio (aHR) 1.79, 95\% CI 1.20 to 2.67). ${ }^{20}$ Maternal smoking during pregnancy may increase the frequency of lower respiratory tract infections, but the evidence is not strong enough to infer a causal relationship. ${ }^{21}$

To date, there have been no systematic reviews synthesising the available empirical studies related to tobacco exposure during pregnancy and infant wheezing, apnoea and lung function in the first 12 months of life. Thus, there is a need to synthesise the latest research evidence and to identify any gaps.

Although it is often difficult to separate the role of prenatal from postnatal exposure, it has been recognised that fetal environmental exposures-during embryogenesis-can lead to time and tissue-specific effects. Moreover, each tissue has a critical window of exposure when it is more sensitive to environmental influences. This review aims to examine the association of exposure to active tobacco use during pregnancy and the offspring's subsequent respiratory health (wheezing and apnoea diagnosis) and lung function in the first 12 months of life. Additionally, we systematically reviewed and metaanalysed the main features, methodological quality and results of the included studies.

\section{METHODS}

\section{Protocol and registration}

The review protocol has been registered at the International Prospective Register of Systematic Reviews (PROSPERO).

\section{Eligibility criteria}

We included case-control and cohort studies that examined the relationship between active tobacco use during pregnancy and offspring lung function parameters (tidal breathing parameters and flow volume measurements during thoracoabdominal compression) and respiratory health outcomes (wheezing and apnoea) within the first 12 months of life.

The respiratory health outcomes were defined based on physician diagnosis, data linkage records or self-report. Lung function parameters were measured by a diverse range of sophisticated lung function tests. Any report of outcomes made within the infant's first 12 months of life was included.

We excluded studies conducted only on exposure to secondhand smoke or environmental tobacco smoke, and studies of pregnant women with substance use disorder or those who were HIV-positive. It was not considered feasible to search non-English-language publications. Reviews, conference publications and grey literature were also excluded.

\section{Information sources}

We developed a comprehensive search strategy. The search for potentially eligible studies was conducted in June 2020, and no limits were placed on the date of publication. Five databases were searched. The databases included were MEDLINE, EMBASE, Cochrane, CINAHL (Cumulative Index to Nursing and Allied Health Literature), and Maternity and Infant Care. The retrieved studies were then assessed and classified according to the eligibility criteria.

The following was the search strategy used for MEDLINE (via PubMed): ("pregnancy" (MeSH) OR "pregnancy" (Text word) OR "pregnant" (Text word) OR "maternal 
exposure" (MeSH) OR "maternal exposure" (Text word)) AND ("smoking" (Text word) OR "smoking" (MeSH) OR "tobacco" (MeSH) OR "tobacco smoking" (Text word) OR "tobacco use" (Text word)) AND ("nicotine" (Text word) OR "nicotine" (MeSH)) AND ("lung" (MeSH) OR "lung" (Text word) OR "lung diseases" (MeSH) OR "respiratory outcomes" (Text word) OR "asthma" (MeSH) OR "apnea" (MeSH) OR "apnoea" (Text word) OR "wheez" (Text word) OR "forced expiratory flow" (Text word) OR "forced expiratory volume" (MeSH) OR "lung compliance" (MeSH)) AND ("infant" (MeSH) OR "infant" (Text word)) AND ("case-control studies" (Text word) OR "case-control studies" (MeSH) OR "casecontrol study" (Text word) OR "study, case-control" (Text word) or "studies, case-control" (Text word) OR "casecomparison studies" (Text word) OR "comparative study" (MeSH) OR "retrospective studies" (MeSH) OR "retrospective studies" (Text word) OR "prospective studies" (Text word) or "prospective studies" (MeSH) OR "cohort studies" (MeSH) OR "cohort studies" (Text word)). This keyword strategy was adapted and reviewed to fit the other electronic databases. Duplicates were excluded and two reviewers (EDQA and CRDSS, both nurses completing their $\mathrm{PhD}$ ) independently assessed and reviewed the titles and abstracts of the studies found. All disagreements were settled by consensus between the authors.

Additional relevant studies were checked through the reference list of the included studies. From those, only original manuscripts were included. There was no attempt made to contact the authors of the included manuscripts.

\section{Data extraction}

A data extraction tool using Microsoft Excel (2019) was used to extract the following information from the studies: title, authors, country of the study, year of publication, data collection period, study design, tobacco product used by the mother, definition of the outcome, sample characteristics, confounding variables and the estimated risk with respective CIs. One reviewer (EDQA) extracted the data from the full texts included, and a second reviewer (CRDSS) checked 100\% of the data extracted for uniformity.

There were two studies where the respiratory outcome reported was initially categorised as asthma. ${ }^{22} 23$ However, after a more in depth inspection by the authors and further analysis by a paediatric respiratory and sleep medicine specialist, it was agreed that those studies should be categorised as a wheezing outcome instead because of the lack of consistency of asthma definition. Those studies were included in the meta-analysis since the definition of asthma given was more related to wheezing in infancy.

\section{Assessment of risk of bias}

The quality of the articles was assessed independently by two reviewers (EDQA and CRDSS) and scored based on the methodological quality using the Newcastle-Ottawa Scale (NOS), ${ }^{24}$ as recommended by the Cochrane Collaboration. The NOS rates quality for group selection, group comparability and determination of any exposure or outcome for case-control or cohort studies. Each item can be awarded one point (marked as a star*), except for the comparability item, which may receive a score of one or two stars. Studies are then classified as low quality (1-3 points), moderate quality (4-6 points) and high quality (7-9 points).

The population of interest was infants up to 12 months of age with data on respiratory health outcomes (wheezing and apnoea) and lung function parameters available, born to women who used tobacco products at any time during pregnancy versus women who did not use tobacco products during pregnancy. Information on the number of cigarettes smoked, socioeconomic status and education level was collected where available. For the meta-analyses, the odds ratio (OR), relative risk (RR) and mean differences (MD) were the effects of interest measured with a 95\% CI. ${ }^{25}$ The pooled OR, RR and MD were given for the random effect model using the generic inverse variance method. ${ }^{26}$ To better describe heterogeneity, the I-squared statistic $\left(\mathrm{I}^{2}\right)$ was assessed, according to Higgins and Thompson. ${ }^{27}$ Heterogeneity was quantified as low, moderate and high, with upper limits of $25 \%, 50 \%$ and $75 \%$ for $\mathrm{I}^{2}$, respectively. ${ }^{28}$ Heterogeneity between studies was investigated using metaregression and further analysis to investigate the influence of other factors was performed using subgrouping analysis and sensitivity analysis. The subgroup analyses were performed by sample size $(<1000$ vs $>1000)$, study quality (moderate vs high) and study design (prospective vs retrospective cohort).

\section{Data synthesis}

Visual inspection of Begg's funnel plot was used to assess publication bias as well as the Egger's regression test at $\mathrm{p}<0.05 .{ }^{29}$ We used STATA software (V.13.0) and Review Manager (RevMan) (V.5.3) for all statistical analyses.

\section{Patient and public involvement}

There was no patient involvement.

\section{RESULTS}

\section{Study selection}

An initial sample of 4423 manuscripts were identified. From these, 3214 titles and abstracts were reviewed and 90 full texts initially examined (figure 1 ).

Twenty-one publications covering 24 studies were identified as relevant. ${ }^{22} 23$ 30-48 Six of the 24 studies assessed infant lung function $(25 \%),{ }^{30-35} 15$ assessed wheezing $(62.5 \%)^{38-48}$ (including two studies that assessed asthma and were reclassified as wheezing ${ }^{22}{ }^{23}$ ) and three assessed apnoea $(15 \%){ }^{36}{ }^{37}$ Meta-analysis was performed for 13 wheezing studies (ten studies expressed the relationship between exposure and disease among the groups by OR and three by RR). Due to differences in methodology, reporting and analysis of lung function, four studies were not included in the meta-analysis. Instead, a narrative review was developed. In the same way, one of the three apnoea studies was not included in the meta-analysis; 


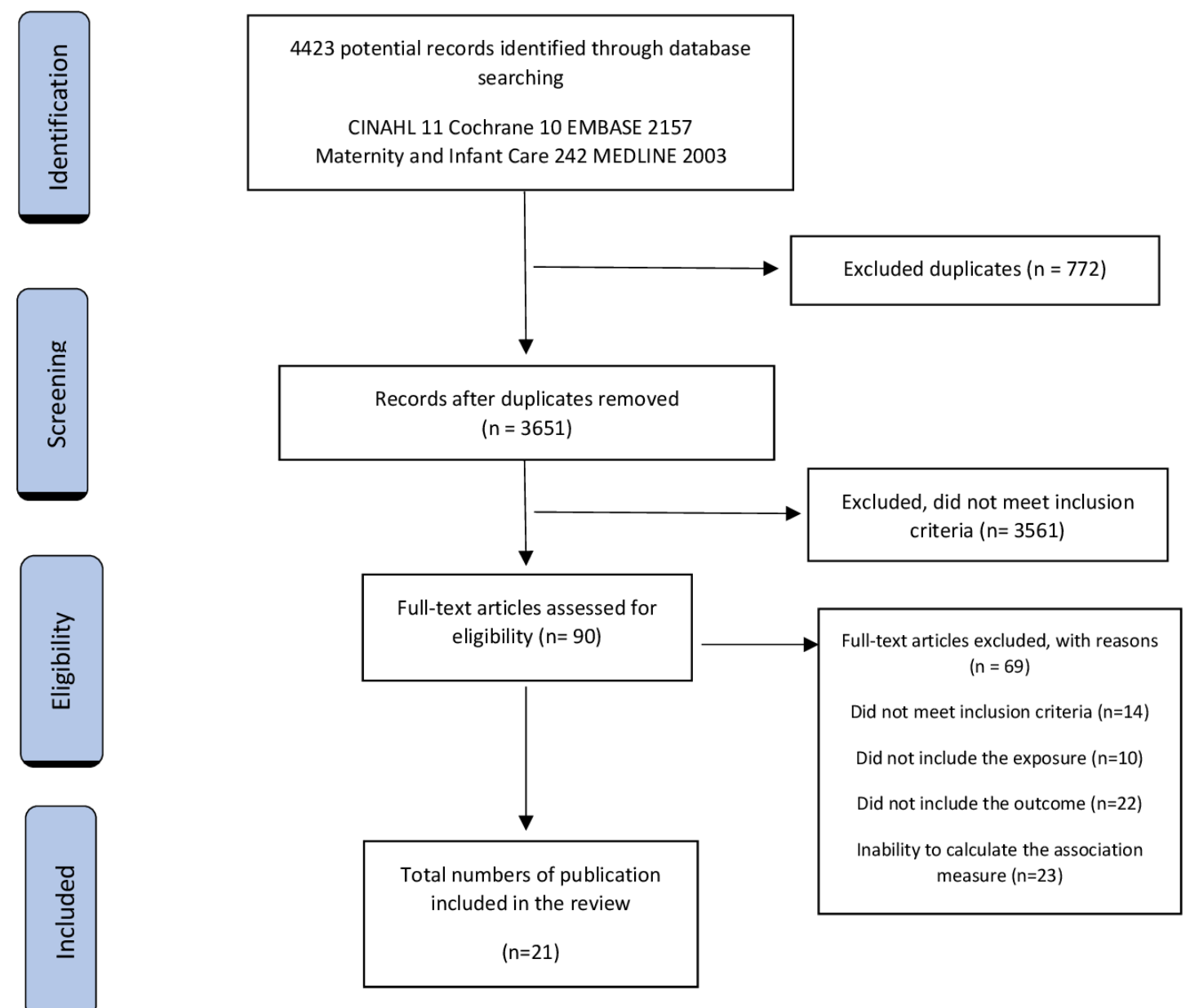

Figure 1 PRISMA (Preferred Reporting Items for Systematic Reviews and Meta-Analyses) flow diagram of the systematic review.

however, a systematic narrative review was developed (table 1).

\section{Study characteristics}

The total population of the original studies was 1677 480 women (table 1). Four studies were conducted in the UK, ${ }^{22} 233940$ three in North America, ${ }^{30} 3842$ four in Australia, ${ }^{31} 333547$ three in Sweden, ${ }^{3648}$ two in the Netherlands, ${ }^{43}{ }^{45}$ one in Spain, ${ }^{44}$ one in Japan, ${ }^{44}$ one in Denmark, ${ }^{34}$ one in Norway, ${ }^{34}$ one in Portugal, ${ }^{41}$ one in Southern Europe $^{37}$ and one in the Czech Republic. ${ }^{39}$ Most studies included women regardless of their age, and only two studies excluded women younger than 17 and 18 years of age, respectively. ${ }^{30}$ Fifteen studies are prospective, six are retrospective (all cohort studies) and two have a case-control design. ${ }^{37} 41$

Data from 21 publications revealed that eight studies took place in hospitals or maternity wards, nine in settings such as clinics and primary care units or via home visits, and four collected data from secondary databases. ${ }^{23} 3648$ The earliest study was published in 1992 in the USA, and the latest was published in 2020 in Sweden. ${ }^{48}$ Four studies presented only crude measures, five studies presented only adjusted measures, and 12 reported both crude and adjusted measures. Two studies did not report on the association between tobacco use and respiratory outcomes using regression analysis (neither crude and adjusted OR nor crude and adjusted RR). However, they contained data on the exposed population versus not exposed population, enabling the crude OR to be calculated. Seven studies were classified of moderate quality. ${ }^{33} 37394043$ The remaining studies were classified as high quality. No study was excluded due to low quality.

\section{MAIN FINDINGS}

Wheezing

Ten studies were included in the meta-analysis, resulting in a total population of 270967 infants. Maternal active smoking during pregnancy was associated with wheezing within the first 12 months of life with an OR of $1.50(95 \%$ CI 1.27 to $1.77, \mathrm{p}<0.01)$ (figure 2). Egger's test $(\mathrm{p}=0.13$ ) and funnel plot indicated no publication bias among the studies included in the meta-analysis. No publication bias was found in the subgroup analyses (Egger's test $p>0.05$ ). A high level of between-study heterogeneity was observed $\left(\mathrm{I}^{2}=57.1 \%, \mathrm{p}=0.01\right)$. The meta-regression revealed that methodology quality $(\mathrm{p}=0.11)$, population size $(\mathrm{p}=0.25)$ 


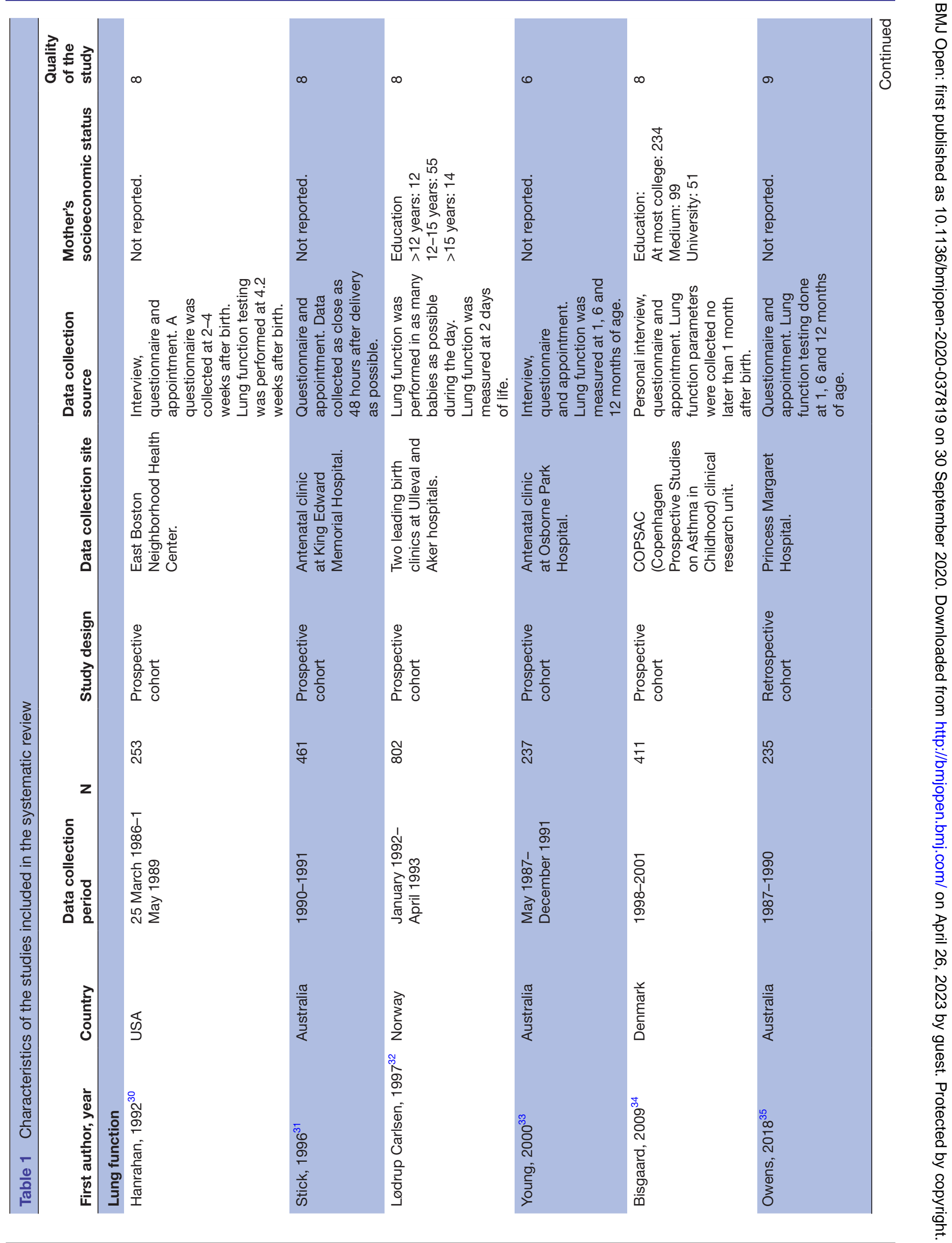




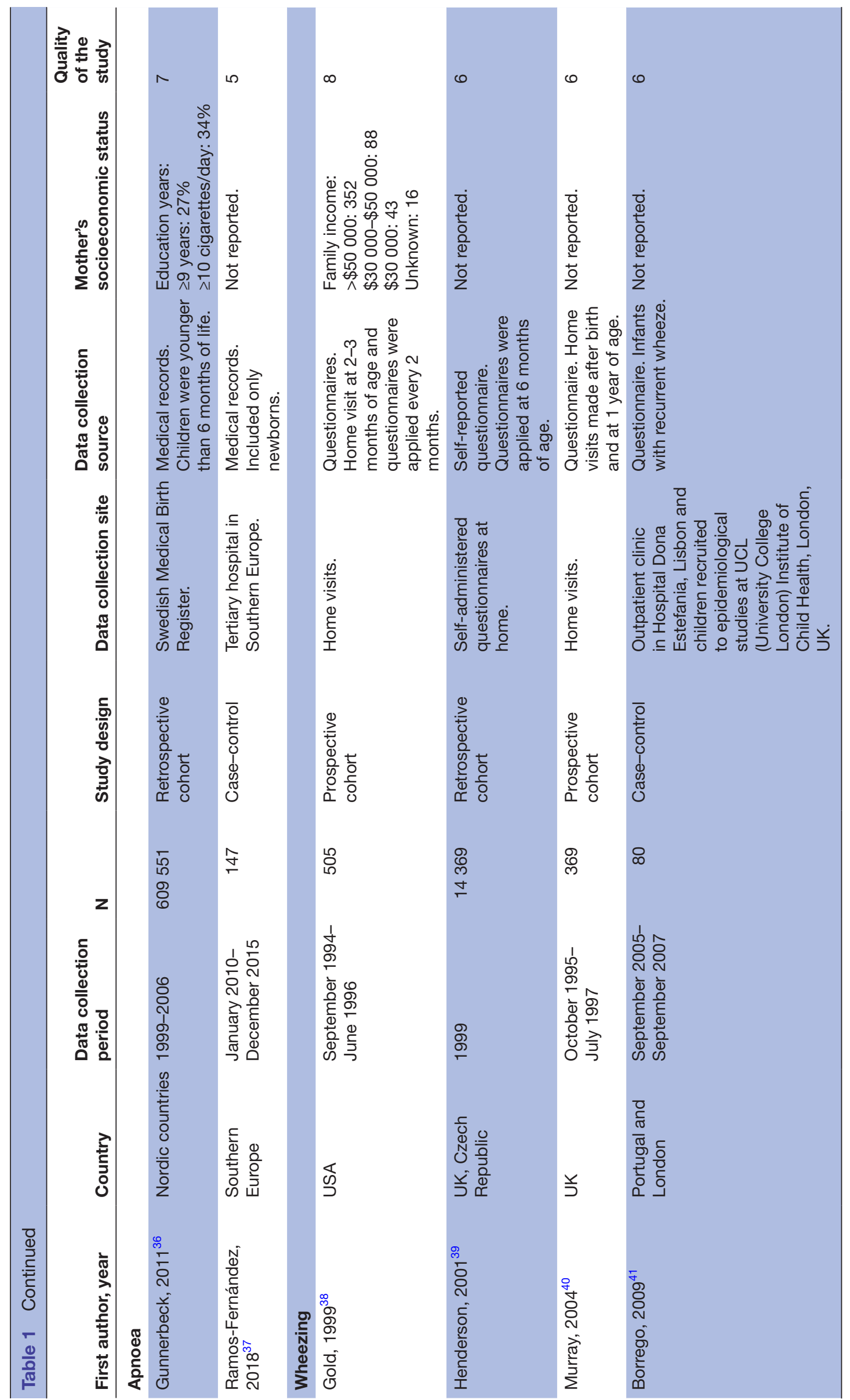

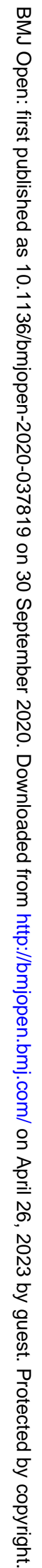




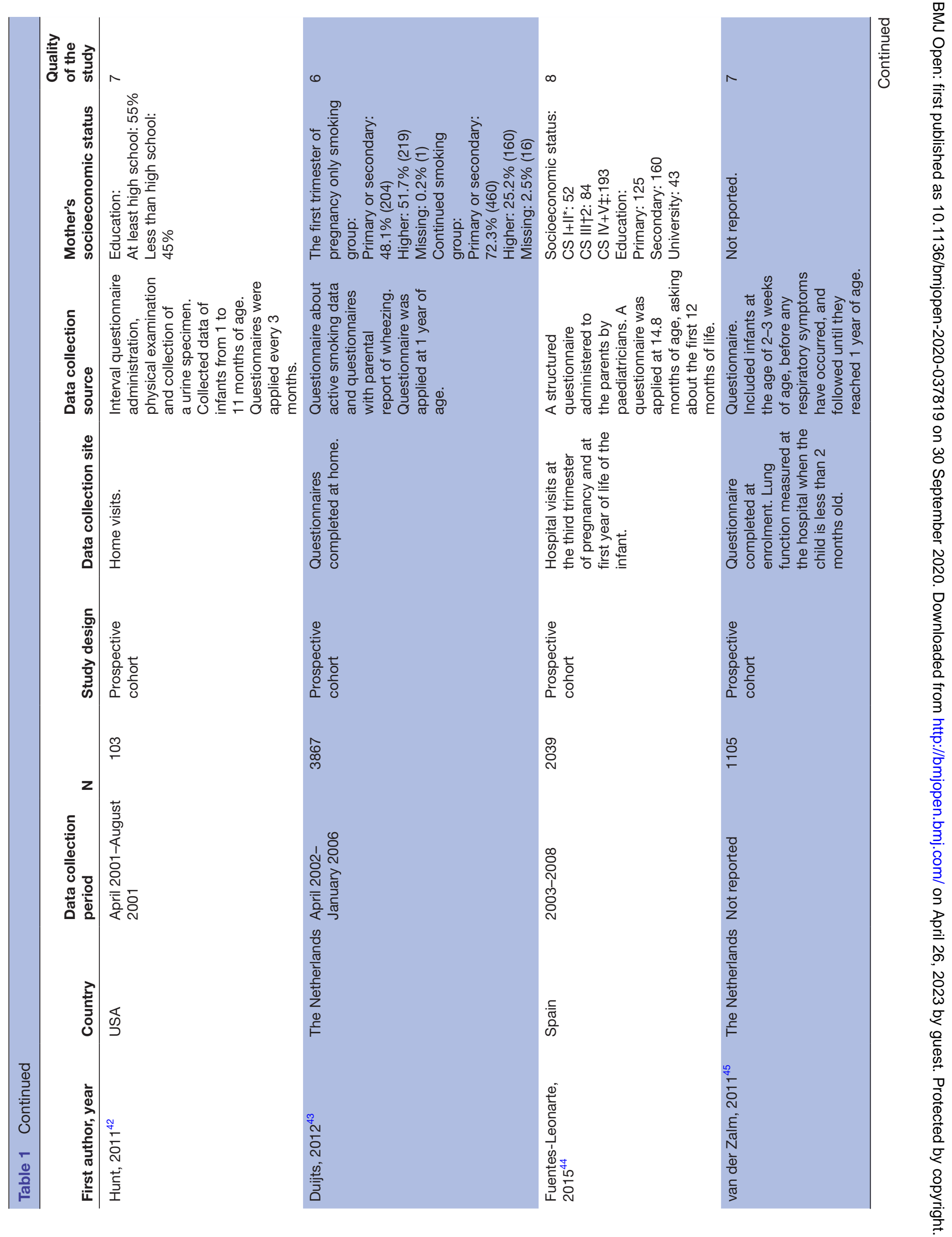




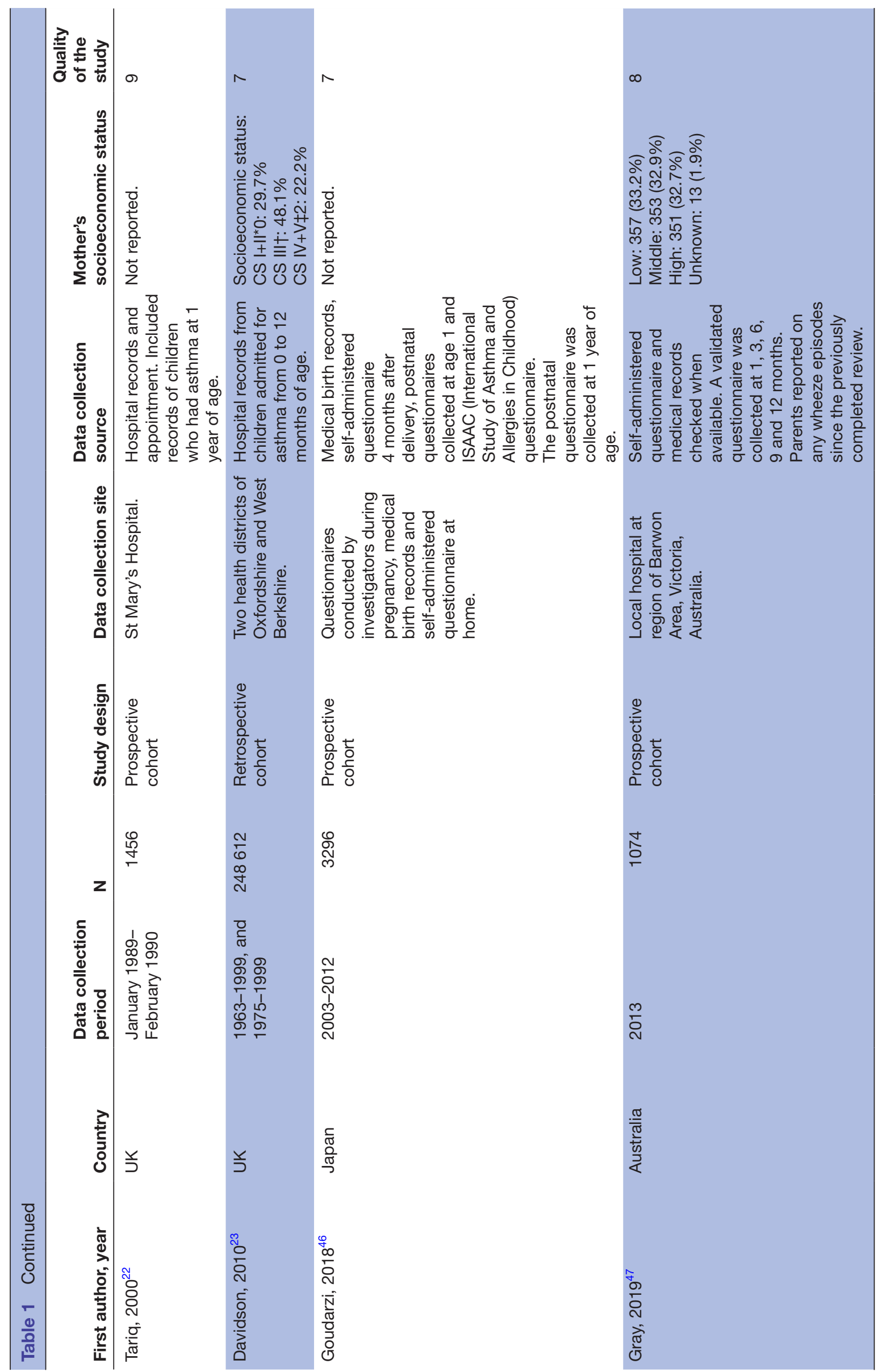




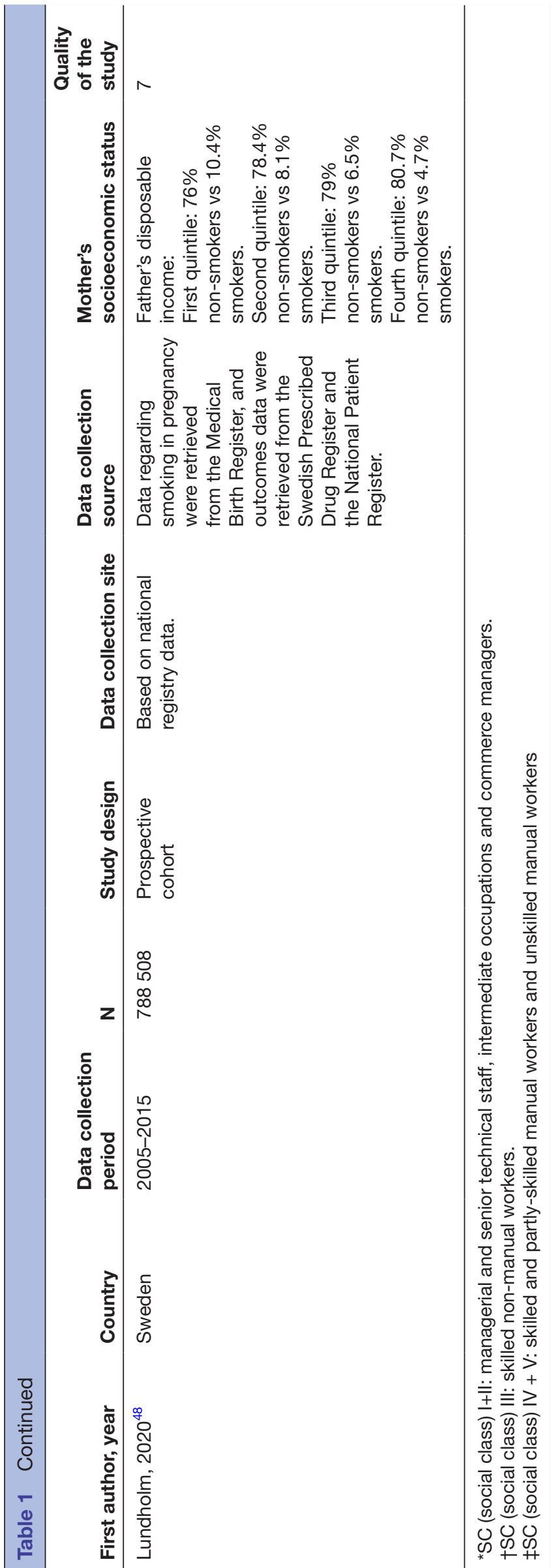

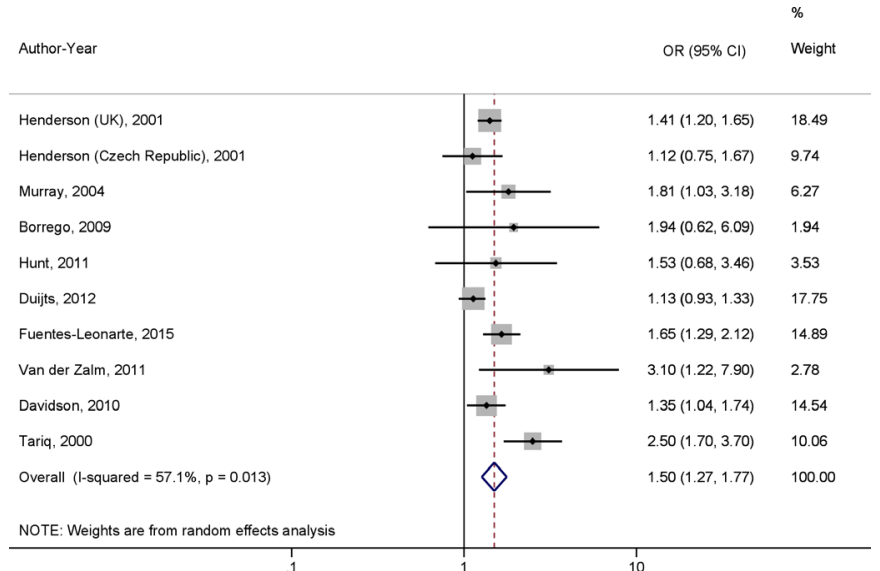

Figure 2 A meta-analysis of the effect of maternal active smoking during pregnancy on wheezing occurrence in infants during the first 12 months of life using OR.

and study design $(\mathrm{p}=0.23)$ had no influence on the heterogeneity.

In the subgroup analyses (table 2), active tobacco use during pregnancy remained associated with wheezing within the first 12 months of life even when the studies were grouped and compared by sample size $(<$ or $\geq 1000$ participants), study design (prospective cohort studies or retrospective cohort studies) and study quality (moderate or high quality). Although the associations remained significant, the subgroup analyses suggested that sample size and study design might be a source of the heterogeneity. The level of heterogeneity in some subgroups was also classified as high $\left(\mathrm{I}^{2}>50 \%\right.$ and $\mathrm{X}^{2}$ $\mathrm{p}<0.05)$.

Three studies that reported only the RR of wheezing were analysed separately ${ }^{38} 46$ as a lack of data on the exposed population versus the not exposed population precluded the calculation of the crude OR. When performing a meta-analysis on those three studies, wheezing within the first 12 months of life was not significantly associated with maternal active smoking during pregnancy, with an RR of 1.30 (95\% CI 0.93 to 1.81, $\mathrm{p}=0.12)$. A high level of between-study heterogeneity was observed $\left(\mathrm{I}^{2}=78.7 \%, \mathrm{p}=0.01\right)$.

One study reported the hazard ratio (HR) for the association between smoking during pregnancy or snuff use during pregnancy and wheezing in the offspring, according to age. ${ }^{48}$ They found a significant association between smoking during pregnancy and wheeze in the first year of life (HR 1.75, 95\% CI 1.50 to 1.65; aHR 1.32, $95 \%$ CI 1.25 to 1.39). However, no significant association between maternal use of snuff during pregnancy and wheeze in the offspring was found (HR 1.20, 95\% CI 0.92 to 1.21 ; aHR $0.86,95 \%$ CI 0.74 to 0.99 ).

The results displayed in the online supplemental table S1 refer to studies that were not included in the metaanalysis. Six studies reported on lung function during the first year of life, ${ }^{30-35}$ and three studies reported on apnoea during the first year of life, covered in two papers. ${ }^{36} 37$ 
Table 2 Subgroup analysis of the effect of active tobacco use during pregnancy on wheezing occurrence in infants

\begin{tabular}{lllcl}
\hline Variable & Groups & OR $\mathbf{( 9 5 \%} \mathbf{C l})$ & $\mathbf{I}^{\mathbf{2}} \mathbf{( \% )}$ & $\mathbf{X}^{\mathbf{2}} \mathbf{p}$ value \\
\hline Sample size & $<1000$ & $1.92(1.31$ to 2.85$)$ & 0.0 & 0.72 \\
Study design & $\geq 1000$ & $1.43(1.19$ to 1.73$)$ & 70.4 & 0.01 \\
Methodological quality & Prospective cohort & $1.72(1.25$ to 2.37$)$ & 74 & 0.00 \\
& Retrospective cohort & $1.36(1.20$ to 1.55$)$ & 0.0 & 0.58 \\
& Moderate & $1.29(1.10$ to 1.51$)$ & 29.3 & 0.23 \\
\hline
\end{tabular}

\section{Lung function in the first 12 months of life}

The review demonstrated mixed results on lung function parameters in children born to mothers who smoked during pregnancy. We were able to perform meta-analyses using two publications that had identical lung function parameters measured and reported, and a comparative analysis conducted. Pooled analysis showed that infants exposed to tobacco smoking during pregnancy showed a trend towards reduced infant lung function at 1 month (mean maximum flow rate at functional residual capacity (V'maxFRC): $-34.59 \mathrm{~mL} / \mathrm{s}, 95 \%$ CI -72.81 to 3.63 , $\mathrm{p}=0.08$ ) compared with infants born to non-smokers $\left(\mathrm{I}^{2}=95 \%, \mathrm{p}<0.01\right)$.

Two studies reported forced expiratory flow measurements in infants. Young $e t a l^{33}$ aimed to examine the lung function of healthy term infants at 1,6 and 12 months of age, using tidal breathing rapid thoracoabdominal compression (RTC) technique in a prospective population-based cohort of 237 infants. They found a significant reduction in maximal forced expiratory flow at functional residual capacity (V'maxFRC) in infants born to smoking mothers throughout the first year of life. As V'maxFRC is a measure of partial forced expiratory flow, this result indicates intrapulmonary airway dysfunction in the first year of life associated with intrauterine tobacco smoke exposure. Bisgaard and collaborators ${ }^{34}$ measured baseline lung function in 404 neonates using the raised volume RTC technique, which allows the determination of flow volume parameters across the entire vital capacity. They reported that maternal smoking was associated with a $7 \%$ decrease in forced expiratory flow at 0.5 second.

Two studies reported tidal breathing parameters without employing RTC technique. Lødrup Carlsen $e t a b^{2}$ aimed to describe lung function in healthy newborns and to assess the influence of in utero tobacco smoke exposure on the tidal breathing and respiratory mechanics in 803 healthy infants. Measurements were made at 2.7 days of life (range 1-9 days), and they found that those exposed in utero to active maternal daily smoking had a nonsignificant reduction in the mean ratio of time to reach peak expiratory flow to total expiratory time (tPTEF:tE) compared with non-exposed infants (0.31 vs 0.32 ). They also reported that mean total respiratory system compliance was non-significantly lower in infants exposed to tobacco smoke compared with those non-exposed (3.92 vs $\left.4.18 \mathrm{~mL} / \mathrm{cmH}_{2} \mathrm{O}\right)$. Another study conducted by Stick and collaborators ${ }^{31}$ aimed to assess the prenatal factors that can adversely affect lung function in newborns (48 hours after birth) in 500 healthy infants. They measured tPTEF:tE using respiratory inductance plethysmography. They reported that significantly lower values of tPTEF:tE were associated with maternal smoking. They showed that infants born to mothers who smoked $>10$ cigarettes a day had the lowest mean tPTEF:tE ( $\beta$ estimate $=-0.05$, 95\% CI -0.01 to $-0.09, \mathrm{p}<0.05)$.

\section{Apnoea}

Two studies ${ }^{36} 37$ explored the effect of smoking during pregnancy and were included in a meta-analysis, resulting in a total population of 502836 infants. In this metaanalysis, apnoea in the first 12 months of life was not significantly associated with maternal active smoking during pregnancy (OR 2.20, 95\% CI 0.76 to $6.10, \mathrm{p}=0.13$ ). A high level of between-study heterogeneity was observed $\left(\mathrm{I}^{2}=68.1 \%, \mathrm{p}=0.08\right)$.

In a nationwide Swedish cohort study, ${ }^{36}$ the association between altered cardiorespiratory control and maternal tobacco smoking during pregnancy was investigated in infants. Furthermore, this study explored if infants born to mothers who used Swedish snuff (snus) during pregnancy had altered cardiorespiratory control. Tobacco use was determined during the first antenatal visit and classified as no use, snus use, moderate tobacco smoking or heavy smoking. Apnoea was classified according to the International Classification of Diseases, 10th revision. ${ }^{49}$ This study revealed that infants born to snus users are at a twofold higher risk for neonatal apnoea compared with infants born to non-tobacco users (OR 2.24, 95\% CI 1.52 to $3.32, \mathrm{p}<0.01$; aOR $1.96,95 \%$ CI 1.30 to $2.96, \mathrm{p}<0.01$ ).

\section{DISCUSSION}

Our review summarises the findings of studies that have examined the association of active tobacco use during pregnancy and wheezing, lung function and apnoea in the offspring's first 12 months of life. Previous reviews were limited to examining the associations of prenatal and postnatal active and passive smoking with wheezing or asthma in preschoolers and adolescents. Furthermore, a previous review restricted their database search to prospective cohorts, including preschoolers and infants 
in the same target population without analysing age groups separately. ${ }^{50}$

Our systematic review and meta-analysis showed that infants born to mothers who actively smoke during pregnancy are at higher risk of wheezing, which is highly prevalent in infants. For instance, $40 \%$ of infants have been reported to wheeze in the first year of life, and a significant number of them will keep on wheezing later in life. ${ }^{51}$

There is evidence to suggest that frequent and persistent wheezing in infancy may predict respiratory health in later life. ${ }^{52}$ For instance, frequent wheezing is a significant risk factor for later asthma development. ${ }^{53}$ However, it is appreciated that asthma is a complex disease with a high degree of heritability and genetic risk components. ${ }^{54}$ Sonnappa and colleagues ${ }^{52}$ demonstrated that infant wheeze is also associated with abnormal lung function in later life. Several studies have demonstrated that altered lung function in the first weeks of life and before the first wheezing episode is associated with asthma development. ${ }^{556}$ Wheezing, apnoea and reduced lung function in the first 12 months of life may also be associated with younger maternal age, area of residence, lower level income, higher parity, pre-pregnancy weight status, asthma in pregnancy and mode of delivery. ${ }^{57}$ These risk factors may lead to alteration in the inflammatory pathways that can modify the responses to certain stimuli that trigger wheezy illnesses. ${ }^{58}$

Results for infant lung function were non-conclusive. Most infants included in the lung function studies were term (>36 weeks) without perinatal health problems and had no significant congenital anomalies. Our metaanalysis of two lung function studies demonstrated a reduction in V'maxFRC in infants who had in utero exposure to tobacco smoke. Many of the other studies not included in the meta-analysis also showed associations between in utero tobacco exposure and reduced lung function. Despite these consistent associations, it is challenging to draw causative conclusions due to the diversity of methods used to determine lung function in infants, the lack of standardised analysis methods and differences in reporting of lung function parameters and study designs.

Our results suggest that there is scarce evidence to quantify the risk of in utero tobacco exposure in infant lung function. This includes a lack of investigations into the role of ST products in infant lung function and limited studies on infant respiratory health outcomes. Nicotine crosses the placental barrier, and fetal levels in blood and lung closely mimic those measured in the mother's blood. Experimental models suggest that intrauterine nicotine exposure results in thickened alveolar walls, increased airway smooth muscle mass and airways hyper-responsiveness, and a mismatch between airway growth and lung size (dysanapsis) ${ }^{59-61}$ The critical period for prenatal nicotine exposure to affect expiratory flow parameters may correspond to the canalicular (16-23 weeks gestation) and saccular (24-36 weeks gestation) period of lung development. ${ }^{61}$
The prenatal and perinatal period is a vulnerable time and a window of opportunity to improve infant lung function and respiratory health outcomes. Our review highlights the importance of alleviating these harmful effects by promoting safe and effective tobacco use cessation interventions in pregnancy. Furthermore, the development of innovative interventions should be promoted in parallel, such as treatment of pregnant women who continue to smoke tobacco with high-dose vitamin C to reduce tobacco smoke-induced oxidative stress and improve infant lung function, ${ }^{62}$ although this approach is yet to be explored for ST use.

Swedish snus is one of the common types of ST, and it has been linked to adverse pregnancy outcomes such as preterm delivery, pre-eclampsia, ${ }^{63}$ oral clefts $^{64}$ and neonatal apnoea. ${ }^{36}$ In this current review, the two studies that focused on ST evaluated the effects of snus and the development of apnoea ${ }^{36}$ and wheezing ${ }^{48}$ in infancy. This tobacco product is consumed orally, being placed under the lip. The user absorbs a high nicotine dosage with this type of tobacco product, while there are no harmful effects due to combustion products such as carbon monoxide. Consequently, the fetus absorbs primarily pure nicotine along with a range of other tobacco chemicals. ${ }^{65}$ The absorption of nicotine from snus occurs at a slower pace, contrary to smoking tobacco that peaks and declines rapidly. ${ }^{66}$ Our analysis highlights the evidence that shows that infants born to mothers using ST are more likely to develop apnoea, while the effect of smoking tobacco was non-conclusive. ${ }^{36}{ }^{37}$ Of note, Lundholm et $a t^{8}$ found a weak association of snus use and risk of wheeze.

Apnoea aetiology in infants is vast and differs according to infant-age and mechanism of pathology. ${ }^{67}$ The longterm consequences of apnoea in healthy infants have not been completely established. However, complications may include failure to thrive, metabolic alkalosis and respiratory distress, which can be life-threatening. ${ }^{68}$ More studies focusing on the association between tobacco use and apnoea are required.

\section{Strengths and limitations of the review}

This systematic review followed the Preferred Reporting Items for Systematic Reviews and Meta-Analyses tool guide, and the included studies were of high methodological quality, according to Newcastle-Ottawa criteria. Most of the active tobacco use information was collected through a self-administered questionnaire, surveys or interviews. However, many women may not reveal sensitive topics such as smoking status during pregnancy. Others may tend to report an answer in a way they deem to be more socially acceptable than would be their 'true' answer. ${ }^{69}$ Social desirability bias has been previously acknowledged as a cause of inaccurate estimates of association, or overestimate or underestimate risk measures in observational studies. ${ }^{70}$

A limitation of the current study is that in a large amount of the manuscripts, the primary aim did not include the effect of in utero tobacco exposure on 
respiratory outcomes in infancy. It is reasonable to speculate that we might have missed studies with relevant data on the subject that did not show evidence of it in its title or abstract. Besides, information on the quantity and frequency of tobacco use was not discussed in this review due to missing data or differences in the data collection methods of the included studies.

\section{CONCLUSIONS}

This systematic review reinforces the association between in utero tobacco use and poor respiratory health outcomes in the offspring. Meta-regressions for the wheezing studies and subgroup analyses showed this association regardless of aspects such as sample size, study design and study quality. Results for lung function parameters and apnoea were non-conclusive in infants born to mothers who actively smoked during pregnancy. Additionally, ST seems to have different effects on respiratory symptoms. Infants born to mothers who use ST are more likely to develop apnoea, although ST was not associated with wheezing in infancy. However, more studies need to be performed to investigate further the role of ST in respiratory outcomes.

Maternal smoking in pregnancy is a significant modifiable risk factor for pregnancy-related mortality, morbidity and pregnancy outcomes. Also, it is the most important known modifiable risk factor for chronic disease development in the offspring, such as childhood asthma. Therefore, our review highlights that reduction of active smoking in pregnancy should be a primary goal to improve infant lung health. In addition, there is a need to promote optimal lung growth and to monitor respiratory health in infants that were exposed to in utero tobacco use.

\section{Author affiliations \\ ${ }^{1}$ GrowUpWell Priority Research Centre, Hunter Medical Research Institute, University of Newcastle, Newcastle, New South Wales, Australia \\ ${ }^{2}$ School of Medicine and Public Health, University of Newcastle, Newcastle, New South Wales, Australia \\ ${ }^{3}$ Department of Paediatric Respiratory \& Sleep Medicine, John Hunter Children's Hospital, Newcastle, New South Wales, Australia}

\section{Twitter Gillian Sandra Gould @GillianSGould}

Acknowledgements The authors thank Ana Claudia Godoy, who provided insights and expertise to this manuscript.

Contributors EDQA wrote the protocol. EDQA and CRDSS individually performed the abstract extraction and critiqued the literature. AC, VEM, GSG, BB and JM provided insight on the epidemiological aspects of the review and helped draft the manuscript. EDQA, CRDSS, AC, VEM, GSG, BB and JM advised on the background and revised the manuscript. EDQA and JM wrote the first drafts of the manuscript. All authors approved the final version and took responsibility for its content.

Funding The authors have not declared a specific grant for this research from any funding agency in the public, commercial or not-for-profit sectors.

Competing interests None declared.

Patient consent for publication Not required.

Ethics approval Institutional review board approval was not necessary because all data were retrieved from public databases.

Provenance and peer review Not commissioned; externally peer reviewed.
Data availability statement All data relevant to the study are included in the article or uploaded as supplementary information.

Open access This is an open access article distributed in accordance with the Creative Commons Attribution Non Commercial (CC BY-NC 4.0) license, which permits others to distribute, remix, adapt, build upon this work non-commercially, and license their derivative works on different terms, provided the original work is properly cited, appropriate credit is given, any changes made indicated, and the use is non-commercial. See: http://creativecommons.org/licenses/by-nc/4.0/.

ORCID iDs

Ediane De Queiroz Andrade http://orcid.org/0000-0001-8956-2779

Gillian Sandra Gould http://orcid.org/0000-0001-8489-2576

\section{REFERENCES}

1 Lange S, Probst C, Rehm J, et al. National, regional, and global prevalence of smoking during pregnancy in the general population: a systematic review and meta-analysis. Lancet Glob Health 2018;6:e769-76.

2 AlHW. Australia's Mothers and Babies 2017-In Brief. Canberra, Australia: Australia Institute of Health and Welfare, 2019.

3 Health Alo, Welfare. National core maternity indicators. Canberra: AlHW, 2018.

4 Greenhalgh E, Gartner C, Scollo M. InDepth 18A: Smokeless tobacco. In Scollo, MM and Winstanley, MH [editors]. Tobacco in Australia: Facts and issues, 2016. Available: http://www. tobaccoinaustralia.org.au/chapter-18-harm-reduction/indepth-18asmokeless-tobaccoU

5 Asma S, Mackay J, Song S, et al. The GATS atlas. 2015, 2015.

6 Health Alo, Welfare. Alcohol, tobacco \& other drugs in Australia. Canberra: AlHW, 2020.

7 Ratsch AM, Mason A, Rive L, et al. The Pituri Learning Circle: central Australian Aboriginal women's knowledge and practices around the use of $<\mathrm{l}>$ Nicotiana $</ \mathrm{l}>\mathrm{spp}$. as a chewing tobacco. Rural Remote Health 2017;17:4044.

8 Jones M, Lewis S, Parrott S, et al. Re-starting smoking in the postpartum period after receiving a smoking cessation intervention: a systematic review. Addiction 2016;111:981-90.

9 Andres RL, Day MC. Perinatal complications associated with maternal tobacco use. Semin Neonatol 2000;5:231-41.

10 Larsen S, Haavaldsen C, Bjelland EK, et al. Placental weight and birthweight: the relations with number of daily cigarettes and smoking cessation in pregnancy. A population study. Int $\mathrm{J}$ Epidemiol 2018;47:1141-50.

11 Suter MA, Aagaard KM. The impact of tobacco chemicals and nicotine on placental development. Prenatal Diagnosis.n/a(n/a).

12 Zdravkovic T, Genbacev O, McMaster MT, et al. The adverse effects of maternal smoking on the human placenta: a review. Placenta 2005;26 Suppl A:S81-6.

13 Hackshaw A, Rodeck C, Boniface S. Maternal smoking in pregnancy and birth defects: a systematic review based on 173687 malformed cases and 11.7 million controls. Hum Reprod Update 2011;17:589-604.

14 National Center for Chronic Disease P, Health Promotion Office on S Health. Reports of the Surgeon General. The health consequences of Smoking - 50 years of progress: a report of the surgeon General. Atlanta, GA: Centers for Disease Control and Prevention (US), 2014.

15 Noakes PS, Holt PG, Prescott SL. Maternal smoking in pregnancy alters neonatal cytokine responses. Allergy 2003;58:1053-8.

16 Chahal N, McLain AC, Ghassabian A, et al. Maternal smoking and newborn cytokine and immunoglobulin levels. NICTOB 2016;63:ntw324-796.

17 Hayatbakhsh MR, Sadasivam S, Mamun AA, et al. Maternal smoking during and after pregnancy and lung function in early adulthood: a prospective study. Thorax 2009;64:810-4.

18 Gibbs K, Collaco JM, McGrath-Morrow SA. Impact of tobacco smoke and nicotine exposure on lung development. Chest 2016;149:552-61.

19 McEvoy CT, Spindel ER. Pulmonary effects of maternal smoking on the fetus and child: effects on lung development, respiratory morbidities, and life long lung health. Paediatr Respir Rev 2017;21:27-33

20 Grabenhenrich LB, Gough H, Reich A, et al. Early-Life determinants of asthma from birth to age 20 years: a German birth cohort study. $J$ Allergy Clin Immunol 2014;133:979-88.

21 National Center for Chronic Disease P, Health Promotion Office on S, Health. Reports of the Surgeon General. The health consequences 
of Smoking-50 years of progress: a report of the surgeon General. Atlanta, GA: Centers for Disease Control and Prevention (US), 2004.

22 Tariq SM, Hakim EA, Matthews SM, et al. Influence of smoking on asthmatic symptoms and allergen sensitisation in early childhood. Postgrad Med J 2000;76:694-9.

23 Davidson R, Roberts SE, Wotton CJ, et al. Influence of maternal and perinatal factors on subsequent hospitalisation for asthma in children: evidence from the Oxford record linkage study. BMC Pulm Med 2010;10:14

24 Peterson J, Welch V, Losos M, et al. The Newcastle-Ottawa scale (NOS) for assessing the quality of nonrandomised studies in metaanalyses. Ottawa: Ottawa Hospital Research Institute, 2011.

25 Petrie A, Bulman JS, Osborn JF. Further statistics in dentistry part 8: systematic reviews and meta-analyses. Br Dent $J$ 2003;194:73-8.

26 Borenstein M, Hedges LV, Higgins JP, et al. Introduction to metaanalysis. John Wiley \& Sons, 2011.

27 Higgins JPT, Thompson SG. Quantifying heterogeneity in a metaanalysis. Stat Med 2002;21:1539-58.

28 Higgins JPT, Thompson SG, Deeks JJ, et al. Measuring inconsistency in meta-analyses. BMJ 2003:327:557-60.

29 Egger M, Davey Smith G, Schneider M, et al. Bias in meta-analysis detected by a simple, graphical test. BMJ 1997;315:629-34.

30 Hanrahan JP, Tager IB, Segal MR, et al. The effect of maternal smoking during pregnancy on early infant lung function. Am Rev Respir Dis 1992;145:1129-35.

31 Stick SM, Burton PR, Gurrin L, et al. Effects of maternal smoking during pregnancy and a family history of asthma on respiratory function in newborn infants. Lancet 1996;348:1060-4.

32 Lødrup Carlsen KC, Jaakkola JJ, Nafstad P, et al. In utero exposure to cigarette smoking influences lung function at birth. Eur Respir $J$ 1997:10:1774-9.

33 Young S, Sherrill DL, Arnott J, et al. Parental factors affecting respiratory function during the first year of life. Pediatr Pulmonol 2000;29:331-40.

34 Bisgaard H, Loland L, Holst KK, et al. Prenatal determinants of neonatal lung function in high-risk newborns. J Allergy Clin Immunol 2009:123:651-7. 657.e651-654.

35 Owens L, Laing IA, Zhang G, et al. Airway function in infancy is linked to airflow measurements and respiratory symptoms from childhood into adulthood. Pediatr Pulmonol 2018;53:1082-8.

36 Gunnerbeck A, Wikström A-K, Bonamy A-KE, et al. Relationship of maternal snuff use and cigarette smoking with neonatal apnea. Pediatrics 2011;128:503-9.

37 Ramos-Fernández JM, Sánchez-Pérez M, Sánchez-González JM, et al. Apnea in infants hospitalized with pertussis: incidence and gestational smoking association. Pediatr Int 2018;60:943-7.

38 Gold DR, Burge HA, Carey V, et al. Predictors of repeated wheeze in the first year of life: the relative roles of cockroach, birth weight, acute lower respiratory illness, and maternal smoking. Am J Respir Crit Care Med 1999:160:227-36.

39 Henderson AJ, Sherriff A, Northstone K, et al. Pre- and postnatal parental smoking and wheeze in infancy: cross cultural differences. Avon study of parents and children (ALSPAC) study team, European longitudinal study of pregnancy and childhood (ELSPAC) Coordinating centre. Eur Respir J 2001;18:323-9.

40 Murray CS, Woodcock A, Smillie FI, et al. Tobacco smoke exposure, wheeze, and atopy. Pediatr Pulmonol 2004;37:492-8.

41 Borrego LM, Stocks J, Leiria-Pinto P, et al. Lung function and clinical risk factors for asthma in infants and young children with recurrent wheeze. Thorax 2009;64:203-9.

42 Hunt A, Crawford JA, Rosenbaum PF, et al. Levels of household particulate matter and environmental tobacco smoke exposure in the first year of life for a cohort at risk for asthma in urban Syracuse, NY. Environ Int 2011;37:1196-205.

43 Duijts L, Jaddoe VWV, van der Valk RJP, et al. Fetal exposure to maternal and paternal smoking and the risks of wheezing in preschool children: the generation R study. Chest 2012;141:876-85.

44 Fuentes-Leonarte V, Estarlich M, Ballester F, et al. Pre- and postnatal exposure to tobacco smoke and respiratory outcomes during the first year. Indoor Air 2015;25:4-12.

45 van der Zalm MM, Uiterwaal CSPM, Wilbrink B, et al. The influence of neonatal lung function on rhinovirus-associated wheeze. $A m \mathrm{~J}$ Respir Crit Care Med 2011;183:262-7.
46 Goudarzi H, Konno S, Kimura $\mathrm{H}$, et al. Contrasting associations of maternal smoking and pre-pregnancy BMI with wheeze and eczema in children. Sci Total Environ 2018;639:1601-9.

47 Gray LEK, Ponsonby A-L, Lin TX, et al. High incidence of respiratory disease in Australian infants despite low rate of maternal cigarette smoking. J Paediatr Child Health 2019;55:1437-44.

48 Lundholm C, Gunnerbeck A, D'Onofrio BM, et al. Smoking and snuff use in pregnancy and the risk of asthma and wheeze in preschoolchildren-A population-based register study. Clin Exp Allergy 2020;50:597-608.

49 World Health O. ICD-10 : international statistical classification of diseases and related health problems: tenth revision. 2nd ed. Geneva: World Health Organization, 2004.

50 Silvestri M, Franchi S, Pistorio A, et al. Smoke exposure, wheezing, and asthma development: a systematic review and meta-analysis in unselected birth cohorts. Pediatr Pulmonol 2015;50:353-62.

51 Arikoglu T, Batmaz SB, Yildirim DD, et al. Asthma predictive index in relation to respiratory mechanics by impulse oscillometry in recurrent wheezers. Allergol Immunopathol 2018;46:190-5.

52 Sonnappa S, Bastardo CM, Wade A, et al. Symptom-pattern phenotype and pulmonary function in preschool wheezers. J Allergy Clin Immunol 2010;126:519-26. e517.

53 Lasso-Pirot A, Delgado-Villalta S, Spanier AJ. Early childhood wheezers: identifying asthma in later life. J Asthma Allergy 2015;8:63-73.

54 Castro-Rodríguez JA, Holberg CJ, Wright AL, et al. A clinical index to define risk of asthma in young children with recurrent wheezing. Am J Respir Crit Care Med 2000;162:1403-6.

55 Sánchez-Solís M. Early lung function and future asthma. Front Pediatr 2019;7:253.

56 Malmström K, Malmberg LP, O'Reilly R, et al. Lung function, airway remodeling, and inflammation in infants: outcome at 8 years. Ann Allergy Asthma Immunol 2015;114:90-6.

57 Carter JH, Woolcott CG, Liu L, et al. Birth weight for gestational age and the risk of asthma in childhood and adolescence: a retrospective cohort study. Arch Dis Child 2019;104:179-83.

58 Szefler SJ, Chmiel JF, Fitzpatrick AM, et al. Asthma across the ages: knowledge gaps in childhood asthma. J Allergy Clin Immunol 2014;133:3-13.

59 Sandberg KL, Pinkerton KE, Poole SD, et al. Fetal nicotine exposure increases airway responsiveness and alters airway wall composition in young lambs. Respir Physiol Neurobiol 2011;176:57-67.

60 Wongtrakool C, Roser-Page S, Rivera HN, et al. Nicotine alters lung branching morphogenesis through the alpha7 nicotinic acetylcholine receptor. Am J Physiol Lung Cell Mol Physiol 2007;293:L611-8.

61 Wongtrakool C, Wang N, Hyde DM, et al. Prenatal nicotine exposure alters lung function and airway geometry through $\alpha 7$ nicotinic receptors. Am J Respir Cell Mol Biol 2012;46:695-702.

62 McEvoy CT, Milner KF, Scherman AJ, et al. Vitamin C to decrease the effects of smoking in pregnancy on infant lung function (VCSIP): rationale, design, and methods of a randomized, controlled trial of vitamin $C$ supplementation in pregnancy for the primary prevention of effects of in utero tobacco smoke exposure on infant lung function and respiratory health. Contemp Clin Trials 2017;58:66-77.

63 England LJ, Levine RJ, Mills JL, et al. Adverse pregnancy outcomes in snuff users. Am J Obstet Gynecol 2003;189:939-43.

64 Gunnerbeck A, Edstedt Bonamy A-K, Wikström A-K, et al. Maternal snuff use and smoking and the risk of oral cleft malformations--a population-based cohort study. PLoS One 2014;9:e84715.

65 Nordenstam F, Norman M, Wickström R. Blood pressure and heart rate variability in preschool children exposed to smokeless tobacco in fetal life. J Am Heart Assoc 2019;8:e012629.

66 Benowitz NL, Porchet $\mathrm{H}$, Sheiner L, et al. Nicotine absorption and cardiovascular effects with smokeless tobacco use: comparison with cigarettes and nicotine gum. Clin Pharmacol Ther 1988;44:23-8.

67 Kondamudi NP, Wilt AS. Infant Apnea. In: StatPearls [Internet]. StatPearls Publishing, 2019.

68 Katz ES, Mitchell RB, D'Ambrosio CM. Obstructive sleep apnea in infants. Am J Respir Crit Care Med 2012;185:805-16.

69 Lavrakas PJ. Encyclopedia of survey research methods. Sage Publications, Inc, 2008.

70 Althubaiti A. Information bias in health research: definition, pitfalls, and adjustment methods. J Multidiscip Healthc 2016;9:211. 